\title{
Toward An Optimum Return From Crop Plants
}

\author{
Xian-Jun Song • Motoyuki Ashikari
}

Received: 5 September 2008 / Accepted: 31 October 2008/Published online: 18 November 2008

(C) Springer Science + Business Media, LLC 2008

\begin{abstract}
The increasing world population and global climate change have made optimizing crop plant return both crucial and urgent. Furthermore, improved understanding of crop yield potential as well as the implementation of related crop management strategies might be important components of a new green revolution. Notably, grain size (weight) and grain number are both essential components of crop yield potential; great progress has recently been made in understanding the genetic and molecular regulation of these traits. This knowledge would be helpful for improving crop yields using traditional and marker-assisted selective breeding strategies combined with genetic modification of local elite varieties.
\end{abstract}

Keywords Grain size and grain number - Grain productivity Genetic and molecular regulator. Crop plants

\section{Introduction}

Food security issues have moved to the top of the global agricultural agenda in response to recent soaring global food prices and are a long-term concern for humans worldwide. It is of central importance to enhance crop production in order to feed the increasing world population. Our understanding of global climate issues is incomplete, and climate change will continue in the next decade, which may have profound and direct impacts on global food security [8]. Furthermore, the recent increase in planting of crops for bioenergy at the expense of food production will further complicate future food security $[71,75]$. Thus,

X.-J. Song $\cdot$ M. Ashikari $(\bowtie)$

Bioscience and Biotechnology Center, Nagoya University,

Nagoya 464-8601, Japan

e-mail: ashi@agr.nagoya-u.ac.jp breeders throughout the world are currently faced with the challenge of improving crop yields to avoid a potentially severe global food shortage.

Many important agronomic traits, such as crop yield, are controlled simultaneously by multiple genes (namely, quantitative trait loci, QTLs) and are strongly influenced by the environment [38]. Therefore, to dissect such complex traits into several indispensable components would contribute to our understanding of this intractable issue. For example, in rice, the yield components usually contain three major elements: grain weight, number of grains per panicle, and panicle number per plant $[20,67$, 81]. Similarly, wheat yield potential is determined by three major components: number of tillers per plant, average number of kernels per spike, and average kernel weight [6]. Undoubtedly, the disaggregation of crop yield into several essential components will provide achievable targets not only for basic research on yield formation mechanisms but also for use in crop yield breeding programs.

In recent years, substantial progress has been made in exploring the molecular basis of plant yield potential. A number of key genetic and molecular regulators of yield component traits, especially seed size and number, have been identified. Examples of these regulators are Gnla [3] and $G h d 7$ [81], which control rice grain number, and $G W 2$ [67] and $q S W 5$ [65], which primarily affect grain size. These factors have all shown the potential for increasing overall yield. This review aims to summarize the genetic and molecular regulators related to seed size development and to the different number of seeds per panicle.

\section{Control of seed size-weight}

In flowering plants, successful seed set depends on the success of double fertilization, which results in the 
formation of a healthy seed and hence the coordinated development of the resultant diploid embryo, triploid endosperm, and maternal ovule (the integuments ultimately constitute the seed coat). Each part of a seed represents a different genetic origin $[39,58]$. This unique aspect of the seed makes its developmental pattern different from that of other plant organs, such as the shoot, root, or leaf. In monocots, such as cereals, and some dicots, the endosperm cells contribute the major volume of the mature seed and supply nutrients to the embryo upon germination, while, in Arabidopsis and many other dicots, the endosperm cells eventually degenerate and are replaced by the embryo. However, in all cases, the initial growth of the endosperm is the major determinant of seed growth [69]. Moreover, the final sizes of plant organs, including seeds, are primarily defined by internal developmental signals [45, 53, 54]. A summary of our knowledge of genetic and molecular regulation of seed size follows. For convenience, we provide a classification outline of the regulating factors, such as genomic imprinting, plant hormone signals, metabolic signals and developmental pathways, and the RING-type E3 ubiquitin ligase.

\section{Genomic imprinting effects on the control of seed size}

As far as the control of seed development and seed size are concerned, genomic imprinting effects are indispensable. Evidence comes from Arabidopsis interploidy crosses, in which viable seeds are larger than normal when the paternal genome is in excess, whereas extra maternal genome copies produce smaller viable seeds $[48,58]$. Similar results were obtained in reciprocal crosses between wild-type and transgenic DNA methyltransferase gene MET1 antisense plants [46, 79].

Genomic imprinting is a form of epigenetic modification, in which the alleles of the imprinting genes are expressed differently in the filial generations, depending on whether they are inherited from the male or female parent [27]. In flowering plants, the endosperm is an important site of imprinting [26], and the established function of genomic imprinting is to govern endosperm development before and after fertilization by repressing target gene expression, and thereby influencing seed development; thus, mutations in the imprinting genes usually lead to seed abortion [13, 29, 42, 43]. A key feature of genomic imprinting is that the imprinted alleles carry some form of differential epigenetic mark, such as DNA methylation and/or histone modification [39]. To date, two hypotheses have been proposed to explain endosperm genomic imprinting; one is the parental conflict theory, key points of which involve different patterns in allocation of resources from maternal tissue to offspring depending on the origin of paternal or maternal alleles [44, 79]; the other hypothesis is a dosage effect, in which seed development primarily depends on a normal ratio of maternal and paternal genomes in the endosperm [64, 79], where any disturbance of the normal ratio will lead to seed abortion or viable seeds of different sizes.

In the developing endosperm, maternal alleles of Arabidopsis FIS class genes MEDEA (MEA), FERTILIZATION INDEPENDENT SEED2 (FIS2), FERTILIZATION INDEPENDENT ENDOSPERM (FIE), and MSII are expressed, whereas the paternal alleles are silenced due to imprinting repression [10, 29, 40, 42, 43, 56]. MEA and FIE encode a SET domain and WD motif protein, respectively, both of which are similar to relevant members of the Drosophila polycomb group (PcG) proteins [29, 57]. PcG proteins function in large complexes to methylate histones and modify chromatin, thus maintaining allele-specific suppression of their target genes [27, 60]. A direct interaction was established between MEA and FIE [46]; however, there is no interaction between either MEA or FIE and FIS2, a zinc finger motif-containing protein [47]. Subsequently, the WD-40 domain protein MIS1 was shown to be a component of the MEA-FIE complex that plays an essential role in seed development $[42,43]$. However, the maternal expression of $M E A$ depends on the activity of DEMETER (DEM), a helix-hairpin-helix DNA glycosylase, which is exclusively expressed in the central cell and is responsible for the removal of DNA methylation of the maternal $M E A$ allele, where the expressed maternal allele of $M E A$ mediates its silencing of the paternal allele [13, 27]. Usually, in a cross using the fis mutant (mea, fis 2, fie, and mis1) as the female parent, almost all seeds undergo endosperm overproliferation, embryo arrest, and seed abortion [34]. In animals, PcG complexes regulate genes responsible for cell proliferation. One function of FIS is to prevent the onset of central cell proliferation and endosperm development prior to fertilization and to repress endosperm growth and development after fertilization [34].

The only known paternally expressed and maternally repressed gene, PHERES1 (PHE1), which encodes an ancient type I class of MADS-box protein, is under the direct epigenetic control of PcG proteins [42, 43], and the expression of $M E A$ is causal to the parent-of-origindependent expression of PHE1 [44]. Hence, it was proposed that the upregulated expression of maternal PHE1 in the mea mutant causes the endosperm and embryo of mea seeds to overproliferate after fertilization and eventually abort [42, 43]. Consistent with this, PHE1 is expressed transiently after fertilization in both the embryo and the endosperm [42, 43]. Furthermore, reduced expression of PHE1 in a mea mutant background can rescue the mea seed abortion phenotype $[42,43]$. It is noteworthy that reducing $P H E 1$ expression levels in the mea background 
using an antisense transgenic strategy cannot only rescue mea seed abortion but also results in its transgenic lines bearing heritable and enlarged seeds [42, 43].

Besides the well-studied regulation of FIS genes, various other known genes act maternally to control seed size. One example of maternal sporophytic control of seed size development is associated with transparent testa glabra 2 (ttg2) in Arabidopsis. The mutant ttg2 was originally found to be defective for proanthocyanidin synthesis and mucilage deposition in the seed coat [37]. Interestingly, seed size is much reduced in $\operatorname{tg} 2 / \mathrm{ttg} 2$ seeds, with a $15 \%$ reduction in seed length. The reduction of $\operatorname{ttg} 2$ seed size is coupled to a reduction in cell elongation in the integument and also to precocious endosperm cellularization. However, the $\operatorname{ttg} 2$ mutation is proposed to primarily affect cell elongation in the integument [24]. Consistently, TTG2 encodes a transcription factor of the WRKY family that is expressed strongly in the seed integument and at low levels in the endosperm [24, 37]. As well as TTG2, APETALA2 (AP2) is also involved in maternal sporophytic control of seed size in Arabidopsis. Apart from its welldefined role in flower development in Arabidopsis, however, loss-of-function ap 2 mutations cause the production of seeds that can have twice the mass of wild-type seeds, indicating that $A P 2$ also plays an important role in determining seed size and weight [36]. The ap 2 mutant embryos are larger and have increased cell numbers and cell size. Reciprocal cross experiments revealed the maternal effect of $A P 2$ on seed size [58]. AP2 encodes an AP2/EREBP transcription factor, and the mechanisms by which it carries out its role in regulating seed size are still not fully understood, except that the levels of soluble sugars during seed development point to the possibility of an alteration in sugar metabolism (accumulation patterns of hexose and sucrose; [58]).

Another maternally controlled seed size mutant, lowbeta-amylasel (lbal) was identified in Arabidopsis as a missense mutation of the AtUPF1 gene, yielding seeds that are on average $22 \%$ longer and $35 \%$ heavier than wild-type seeds [82]. Transgenic expression of wild-type AtUPF1 in the mutant background restored its seed-size phenotype [82]. AtUPF1 is an RNA helicase, playing a central role in nonsense-mediated mRNA decay (NMD), which specifically recognizes aberrant mRNAs and targets them for degradation ([5], reviewed by Baker [82]). The lbal mutant was originally isolated as a mutant exhibiting reduced sugar-induced expression of At $\beta$-Amy [52]. Because the NMD pathway is an mRNA surveillance mechanism, seedsize alteration in the lbal mutant is thought to be due to altered posttranscriptional regulation of NMD-targeted gene (s) [82]. Thus, identification of the targeted gene(s) promises to uncover a novel maternal control mechanism underlying seed-size development.

\section{Plant hormone signals influence final seed size}

In higher plants, hormones influence numerous aspects of growth and development [15]. The effects that plant hormones exert on seed-size development can be seen in mutants that are defective in plant hormone biosynthesis or perception [53].

Two rice dwarf mutants, dwarfl $(d 1$; [4]) and dwarf11 $(d 11 ;[72])$, were identified and found to have very similar seed phenotypes, exhibiting shorter grains with dramatically reduced seed length. At the same time, Fujisawa et al. [23] used transgenic rice with antisense suppression of the D1 gene that produced dwarf rice plants with a similar seed phenotype to the $d 1$ mutant. The $d 1$ mutant has phenotypes characteristic of GA deficiency [59], and D1 is the only gene in rice encoding a prototypical heterotrimeric $G$ protein $\alpha$-subunit, which presumably functions in the GA signal transduction pathway [4]. The G protein is thought to transmit the gibberellin signal(s) responsible for the normal development of rice internodes and seeds [23], whereas $d 11$ is a novel cytochrome P450 gene mutant implicated in brassinosteroid (BR) biosynthesis [72]. However, mechanisms underlying seed-size regulation are still unclear for both mutants. Other BR-biosynthesis-defective mutants in rice, such as ebisu dwarf (dwarf2/d2; [33]), BR-deficient dwarf1 (brd1; [32]), and BR-deficient dwarf2 (brd2; [31]), also bear smaller seeds than the wild type; therefore, GA signal transduction and the BR biosynthesis pathway affect crop grain size.

Another mutant in Arabidopsis, megaintegumenta (mnt), which increases seed size and weight, revealed a link between auxin signaling and seed-size control [63]. Extra cell division in the integuments surrounding mnt mutant ovules, resulting in the formation of enlarged seed coats, was proposed to be a major driving force for increased seed size and weight (i.e., integument-led seed growth; [63]). This may in part share similar mechanisms with the rice GW2 gene in controlling seed size and weight [67]. Both cases provide an indication of the importance of growth of the ovule before fertilization in determining final seed size [63]. The mnt mutant phenotype is caused by a complete loss of function of the AUXIN RESPONSE FACTOR 2 (ARF2), which encodes a transcription factor mediating gene expression in response to auxin. Future identification of the direct target(s) of $A R F 2$ will help to clarify the entire scenario.

Cytokinin signals may also exert an influence on seedsize development in higher plants. Evidence comes from experiments in which enhanced cytokinin breakdown occurred in genetically engineered transgenic plants. The mature viable seeds of engineered transgenic Arabidopsis plants that individually overexpress two cytokinin oxidasedehydrogenase genes, $A t C K X 1$ and $A t C K X 3$, were both 
greatly enlarged and approximately twice the weight of wild-type seeds [77]. The enlarged transgenic seeds show a similar increase in embryo size attributable to increases in both cell number and cell size [77]. Similarly, plants carrying the combined mutations of three cytokinin receptor genes, $A H K 2, A H K 3$, and $C R E 1 / A H K 4$, bear seeds that are more than twice as large as those of wild-type plants, primarily due to an increase in the size of their corresponding embryos. This is proposed to be a direct effect of loss of receptor functions and their role in growth control [61]. However, genetic data indicate that the embryo size alteration of the triple-cytokinin-receptor mutant is largely under maternal and/or endospermal control [61].

New studies on an Arabidopsis dal mutant have established a link between abscisic acid (ABA) signals and seed-size regulation. Compared to the wild type, the average seed weight of $d a l$ increased up to $32 \%$, and total seed yield per plant increased more than 10\% [45]. Moreover, molecular cloning of the DAl gene indicates that it encodes a predicted ubiquitin receptor, and overexpression of the mutant $d a 1$ allele in the wild-type background leads to significantly larger seeds than in the wild type [45]. Expression of $D A 1$ can be induced by ABA, and sensitivity to $\mathrm{ABA}$ is greatly reduced in the mutant dal, indicating that ABA signaling may be involved in plant seed-size control. In addition, the $D A 1$ gene may control seed size by restricting the duration of cell division [45], as it has been previously shown that seed ABA content influences cell cycle arrest [21], suggesting the importance of future investigations of $D A 1$ regulation of seed size and development.

\section{RING-type E3 ubiquitin ligase is involved in control of grain size and crop yield}

The "really interesting new gene" (RING) finger proteins are a newly defined family containing a characteristic conserved RING finger motif and play important roles in many cellular processes, including cell cycle progression, oncogenesis, signal transduction, and development [68]. Since first being recognized in 1991, the family has increased to $>200$ proteins across a diverse group of eukaryotes [68]. A number of RING-type proteins function as E3 ubiquitin ligases, recruiting the target proteins for ubiquitin-dependent degradation by the $26 \mathrm{~S}$ proteasome $[19,35,62,80]$.

A newly identified RING-type protein, GW2, was reported to contribute to the molecular regulation of grain width and weight in rice [67]. In a near isogenic line (NIL; GW2) harboring a large grain allele, grain width increased $26.2 \%$ compared to the small grain parental line. Accordingly, the 1,000-grain weight in NIL (GW2) showed a significant increase of up to $49.8 \%$. Most strikingly, the grain yield per plant of NIL (GW2) increased by $19.7 \%$, although a tradeoff between grain size and grain number occurred, where the number of grains per main panicle was reduced by $29.9 \%$ in NIL (GW2). Nevertheless, GW2 is a useful locus for high-yield crop breeding [67].

Map-based cloning delimited $G W 2$ to an $8.2-\mathrm{kb}$ region on chromosome 2 in which only one predicted open reading frame was found, and subsequent sequence analysis identified a 1-bp deletion resulting in a premature stop codon in exon 4 of the large grain allele, which was proposed to explain the natural grain size variation between parental lines [67]. GW2 encodes a RING domain protein with in vitro $\mathrm{E} 3$ ubiquitin ligase activity, and transgenic plants expressing different levels of $G W 2$ can significantly alter the grain size of recipient lines [67]. A reasonable explanation for natural allelic variation is that the truncated protein (encoded by the large grain allele) has lost its substrate-binding domain [67], and future identification and characterization of its target substrate(s) might reveal more information about this type of regulation. Furthermore, data from histological analyses of spikelet hulls before heading suggest that loss of GW2 function increased cell number, and thus the wild-type $G W 2$ negatively regulated cell division by targeting its substrate(s) to proteasomes for proteolysis [67].

To rule out the possibility that increased grain size is associated with lower grain quality, several rice grain quality indices were tested, and the results revealed no reduction in cooking or eating quality in NIL $(G W 2)$ grains [67]. Moreover, GW2 homologs have been found in maize (Zea mays) and wheat (Triticum aestivum); therefore, a crop variety with a suitable grain size could be obtained by genetically modifying $G W 2$ [50].

\section{Metabolic signals and developmental pathways: crucial regulators of final seed size}

As described previously, ap2 mutations result in increased embryo cell number and cell size, probably via metabolic alteration of hexose to sucrose ratios, and thus play a role in controlling seed mass in Arabidopsis [58]. Consistent with this, studies with Vicia faba (fava bean) have suggested that large and small variations in seed size and weight are mainly due to a discrepancy in the carbohydrate status of developing seeds, which is closely correlated with accumulation patterns of cell-wall-bound invertase (VfCWINV1) activity and its mRNA levels, in agreement with mitotic activity of the developing cotyledons [76]. A longer cell division phase in the "large" embryo is associated with a prolonged phase with a higher ratio of hexose to sucrose [76]. In $V . f a b a, V f C W I N V 1$ is mainly expressed in the 
unloading area of the seed coat and is critical to supplying hexoses to fast-dividing embryo and endosperm tissues [7]. Hence, the coordinated regulation of embryo development with that of the maternal seed coat using metabolic signals controls embryo cell division and, consequently, seed size [76].

The first plant invertase-deficient mutant, miniaturel (mnl), was identified in maize (Z. mays; [51]. Compared to the wild type, the $m n l$ endosperm has only $55 \%$ of the cell number and $25 \%$ of the endosperm volume, indicating that the small size of the $m n l$ endosperm is due to a combined effect of impaired cell proliferation and reduced cell size [74]. It has been established that the number of cells formed in the cotyledons or the endosperm is equal to the capacity of the storage organ to accumulate dry matter [76]. Thus, the mnl mutant is marked by a drastic reduction in endosperm weight relative to that of the wild type [12]. The Mnl gene encodes an endosperm-specific isoform of cell-wall-bound invertase, INCW2, which functions in providing hexoses for mitoses, creating appropriate sugar signals [11]. Conversely, INCW2 deficiency may cause a prematurely high ratio of sucrose to hexose in the endosperm, which may favor cell differentiation and starch accumulation over cell division [74].

Comparisons of the activities of the carbon-metabolizing enzymes, sucrose synthase (SuSy; EC2.4.1.13), UDPglucose pyrophosphorylase (UGPase; EC2.7.7.9), and ADPglucose pyrophosphorylase (AGPase; EC2.7.7.27), during seed development between two genotypes of Vigna radiata (mung bean) differing in seed weight were carried out, and the results showed that these enzymes follow a similar pattern; that is, compared to those in small seeds, enzyme activities in large seeds were maintained for a longer period of time [14]. In maize, mutation of the endosperm-specific starch synthetic enzyme gene Shrunken2 (Sh2) increased mature seed weight by $11-18 \%$ [28]. Sh2 encodes the large subunit of the heterotetrameric starch synthesis enzyme, adenosine diphosphoglucose pyrophosphorylase (AGP; EC2.7.7.27), and its mutant had reduced sensitivity to phosphate, an inhibitor of AGP, giving rise to increased seed weight [28]. Interestingly, the increase in seed weight is not associated with a reduced number of seeds per ear [28]. In addition, transgenic wheat ectopically expressing a modified form of the maize Sh2 gene (Sh2r6hs) exhibits increased AGP activity in developing seeds and produces an average of $38 \%$ more seed weight per plant [66].

Mutations of cytosolic glutamine synthetase (GS1) cause reduced seed size, highlighting the importance of nitrogen (N) metabolism in the control of grain production. In maize, mutation of the GS1 isoenzyme gene Gln1-4 leads to a series of reductions in the $G \ln 1-4$ transcript, the amount of expressed GS1 protein, and GS1 activity and, consequently, causes a specific decrease in grain size and production [49].
The Gln1-4 protein is localized to the bundle sheath cells in leaf tissue and is proposed to have a catabolic function in the reassimilation of ammonium released during protein breakdown to provide Gln for kernel growth during grain filling [49]. Consistent with this, the rice knockout mutant of the GS1 homologous gene $O s G S 1 ; 1$ results in a severe reduction in grain filling and thus grain size and production [70]. However, the $O s G S 1 ; 1$ gene has pleiotropic effects on plant development, including plant height, leaf blade length, panicle size, and grain filling [70], whereas the maize Gln14 gene is specifically involved in kernel development [49].

The isolation of two small Arabidopsis seed mutants enabled the identification of two sporophytically acting genes, HAIKU2 (IKU2) and MINISEED3 (MINI3), located on chromosomes 3 and 1, respectively [48]. Cloning of IKU2 and MINI3 enabled the characterization of a leucinerich repeat (LRR) kinase gene and a WRKY class transcription factor, WRKY10; interestingly, expression pattern analyses indicated that both genes, and another mutant locus, ikul [25], may function in the same regulatory pathway governing seed-size development [48]. Compared to the wild type, iku2 and mini3 mutants exhibit a series of similar phenotypes, such as precocious cellularization in endosperm development, retardation in embryo development, and reduction of embryo size [48]. More crucially, both mutant homozygotes can bear viable seeds and are comparable to the wild type in silique size and number of seeds per silique [48]. Coincidently, mutations in another Arabidopsis putative serine-threonine LRR receptor kinase gene, $E X S$, caused strikingly reduced seed size [9]. Consistent with the smaller seeds of exs, these seeds develop slowly, and development of the embryos of smaller seeds is significantly delayed by specifically reducing the cell size [9]. Also, endosperm development in exs mutants is significantly slower than in the wild type [9]. Thus, the EXS gene may act to enhance growth in the embryo and endosperm so as to influence final seed-size determination.

\section{Regulators of cell division and gene transcription influence seed-fruit size}

The control of cell division during organogenesis plays a crucial role in determining the intrinsic final size of organs in higher plants [54]. The role of regulators of cell division can be seen in the case of the Arabidopsis regulatory gene, AINTEGUMENTA (ANT), which is proposed to act as an organ size checkpoint, regulating intrinsic organ (including seed) size by maintaining meristematic competence [54]. Ectopic expression of the $35 \mathrm{~S}:: A N T$ transgene displayed multiple organ (including seed) hyperplasia, resulting mainly from an increase in cell number in both Arabidopsis and tobacco plants. This increase results from an extended 
period of cell proliferation and organ growth. Conversely, loss-of-function ant mutants exhibit defective integument and female gametophyte development [41]. ANT encodes a plant-specific AP2 transcription factor, and while the mechanism by which it affects seed size is still undetermined, it presumably acts in part through regulating cell division in integuments [41].

The first QTL isolated from plants and known to control tomato fruit size, $f w 2.2$, is an established regulator of cell division [16]. fw2.2 could explain approximately $30 \%$ of the fruit weight transition from modern large-fruited cultivars to wild small-fruited relatives, by encoding a RAS-like G-protein that presumably modulates fruit size by controlling carpel cell number before anthesis [22]. Subsequent studies using the small- and larger-fruited NILs indicated that heterochronic regulatory mutations are sufficient for explaining allelic differences in fw2.2 [18]. Also, beyond a primary and direct effect imparted by fw2.2 on fruit size, it also modifies sink-source relationships at the wholeplant level, bringing changes to fruit number, inflorescence number, and flower-fruit abortion rates [55]. Therefore, allelic differences at $f w 2.2$ were found to have no obvious effects on overall yield changes in field tests $[55,73]$.

Apart from fw2.2 regulating cell division, which contributes to drastic fruit size alterations in tomato plants, changes in organ (locule) number of tomato fruits represent another big step in the evolution of extreme fruit size [17, 73]. Recently, a major locus, fascinated, was isolated, and it was found that allelic variation underlying phenotype change points to a regulatory change in a YABBY-like transcription factor [17]. Because the increase in locule number can cause up to a $50 \%$ increase in fruit size, the identification and characterization of the fascinated gene holds great promise for fine-tuning tomato fruit size in breeding programs $[17,73]$.

\section{Genes with no currently assigned biochemical functions are associated with seed size increases and yield improvement}

With more and more genes associated with agriculturally important traits being identified in recent years, the number of genes with no assigned biochemical function has also increased. One major QTL for rice grain width, qSW5 (QTL for seed width on chromosome 5), was recently isolated and characterized [65]. A field test showed that NIL (qSW5) can cause a $>10 \%$ grain yield reduction because of reduced grain size [65]. Although no definable biochemical function has currently been assigned to $q S W 5$, experimental data showed that a deletion has caused a marked increase in seed width and mass by increasing the number of cells in the outer glume of the rice flower [65].

\section{Molecular regulators of grain number traits}

Grain number is also a trait of great interest because of its direct contribution to grain productivity. Although compensation effects, i.e., negative correlations, are often observed between grain size and grain number [1, 30, 55, 58, 67], one example of a primary grain-number-regulating QTL, Gnla, was found to be a regulator of grain yield per plant [3], indicative of a useful locus for increasing grain productivity.

In rice, a QTL for grain number per panicle, Gnl, was mapped on chromosome 1 and later found to consist of two loci, QTLGn1a and QTLGn1b, with a single QTLGnla locus increasing grain number by $21 \%$ [3]. Gnla encodes a gene for cytokinin oxidase-dehydrogenase (OsCKX2), which can effectively degrade cytokinin; hence, reduced expression of $O s C K X 2$ is causal to higher accumulated cytokinin in inflorescence meristems and to increased grain number, leading to a higher yield potential [3]. Moreover, two agriculturally useful traits, grain number ( $G n 1$ locus) and plant height ( $s d l$, the rice Green Revolution gene), have been successfully combined into a common genetic background (QTL pyramiding), thereby generating a new superior variety having both beneficial traits [3].

Also in rice, a single locus (QTLGhd7) was recently identified on chromosome 7 and confirmed to simultaneously exert major effects on three classes of agriculturally important traits including grain number, plant height, and heading date [81]. Of note, NIL plants carrying the large grain-number allele increased grain weight per plant by $50.9 \%$, mainly due to increased grain number per panicle [81]. Cloning, transgenic, and expressional analysis of Ghd7 showed that this locus corresponds to a CCT (CO, CO-like, and TIME of CAB1) domain protein and functions in the photoperiodic flowering pathway upstream of Ehd1 and $H d 3 a$ [81], implying an alteration of panicle size and grain number as a consequence of $G h d 7$ response to photoperiod. In addition, under long-day conditions, elevated Ghd7 expression increases plant height and panicle size and thus grain number, with a concomitant significant delay in flowering [81]. Nevertheless, the use of Ghd7 alone in breeding practices could not simultaneously improve both heading date and crop-yield traits.

In addition, metabolic regulators also play important roles in determining grain number in plants. Transgenic plants with the pSh2::Sh2rhs construct in wheat enhanced seed AGP activity, resulting in an increase in yield (see above). This increased yield is primarily due to the increase in seed number per plant [66]. Since AGP functions to catalyze the rate-limiting reaction in starch biosynthesis in plants, the results imply that genetic modification of the corresponding regulating enzymes along this pathway helps to increase yield in crop plants. 
Like $G \ln 1-4$, another maize GS1 isoenzyme gene, $G \ln 1$ 3 , also functions in the control of grain production. In the knockout mutant $g \ln 1-3$, kernel number is the yield component that is preferentially affected [49]. Conversely, when $G \ln 1-3$ was constitutively overexpressed in leaves, an increase in the amount of GS1 protein and a 30\% increase in grain yield were observed; moreover, this increase in grain yield was proportional to the increase in GS1 enzyme activity [49]. Additionally, Gln1-3 was localized to mesophyll cells and is proposed to provide sufficient $\mathrm{N}$ assimilates to the developing ear to avoid kernel abortion [49]. In the double mutant $\ln 1-3 \ln \ln 1-4$, a cumulative effect exists; that is, both grain size and grain number were reduced [49]. Thus, increasing $\mathrm{N}$-use efficiency is a potential tool for improving yield in crop plants.

\section{Conclusions and perspectives}

An increasing number of key regulators of grain size and grain number have recently been cloned and functionally characterized. Numerous lines of evidence point to diversified pathways contributing to the control of both traits, and this control may involve some overlap of several pathways. The overlap can also be seen in a recent finding in which transgenic rice plants with elevated BR levels exclusively in the stems, leaves, and roots bear more and heavier seeds than wild-type plants, resulting in $15 \%$ to $44 \%$ increases in grain production per plant [78]. Interestingly, these phenotypic changes were associated with alterations of $\mathrm{CO}_{2}$ assimilation and sugar metabolic signals in the flag leaves [78], suggestive of multiple-aspect regulation of grain weight and grain number. Additionally, cross talk between maternal and zygotic control of seed size has been reported [24].

Tremendous efforts have been made to enhance our knowledge of the molecular regulation of both grain size and grain number, and several examples that exhibit successful yield-improving potential have been provided; however, these findings provide only an initial step toward a thorough understanding of crop yield formation. Therefore, in future investigations, apart from improving our understanding of existing regulating factors and fully exploiting these for practical breeding programs, it is necessary to identify and characterize many more novel factors involved in the control of seed size and seed number. To this end, several aspects have been highlighted here. First, it will be helpful to create several suitable exotic genetic libraries as starting materials [83]. Second, emerging genetic approaches should be adopted in order to promote and facilitate crop improvement [71]. In particular, QTL pyramiding provides a useful strategy for effective crop breeding $[2,71]$.

\section{References}

1. Anastasiou E, Lenhard M. Growing up to one's standard. Curr Opin Plant Biol 2007;10:63-9.

2. Ashikari M, Matsuoka M. Identification, isolation and pyramiding of quantitative trait loci for rice breeding. Trends in Plant Sci 2006;11:344-50.

3. Ashikari M, Sakakibara H, Lin SY, Yamamoto T, Takashi T, Nishimura A, et al. Cytokinin oxidase regulates rice grain production. Science 2005;309:741-5.

4. Ashikari M, Wu JZ, Yano M, Sasaki T, Yoshimura A. Rice gibberellin-insensitive dwarf mutant gene Dwarfl encodes the alpha-subunit of GTP-binding protein. Proc Natl Acad Sci U S A 1999;96:10284-9.

5. Baker KE, Parker R. Nonsense-mediated mRNA decay: terminating erroneous gene expression. Curr Opin Cell Biol 2004;16:293-9.

6. Bokan N, Malesevic M. The planting density effect on wheat yield structure. Acta Agriculturae Serbica 2004;9:65-79.

7. Borisjuk L, Rolletschek H, Radchuk R, Weschke W, Wobus U, Weber H. Seed development and differentiation: a role for metabolic regulation. Plant Biol 2004;6:375-86.

8. Brown ME, Funk CC. Food security under climate change. Science 2008;319:580-1.

9. Canales C, Bhatt AM, Scott R, Dickinson H. EXS, a putative LRR receptor kinase, regulates male germ line cell number and tapetal identity and promotes seed development in Arabidopsis. Curr Biol 2002;12:1718-27.

10. Chaudhury AM, Luo M, Miller C, Craig S, Dennis ES, Peacock WJ. Fertilization-independent seed development in Arabidopsis thaliana. Proc Natl Acad Sci U S A 1997;94:4223-8.

11. Cheng WH, Chourey PS. Genetic evidence that invertasemediated release of hexoses is critical for appropriate carbon partitioning and normal seed development in maize. Theor Appl Genet 1999;98:485-95.

12. Cheng WH, Taliercio EW, Chourey PS. The Miniatue1 seed locus of maize encodes a cell wall invertase required for normal development of endosperm and maternal cells in the pedicel. The Plant Cell 1996;8:971-83.

13. Choi Y, Gehring M, Johnson L, Hannon M, Harada JJ, Goldberg $\mathrm{RB}$, et al. DEMETER, a DNA glycosylase domain protein, is required for endosperm gene imprinting and seed viability in Arabidopsis. Cell 2002;110:33-42.

14. Chopra J, Kaur N, Gupta AK. Sustained activities of carbon metabolizing enzymes determine seed size in Vigna radiata (mung bean). Curr Sci. 2007;92:1420-4.

15. Chow B, McCourt P. Plant hormone receptors: perception is everything. Genes Dev 2006;20:1998-2008.

16. Cong B, Tanksley SD. FW2.2 and cell cycle control in developing tomato fruit: a possible example of gene co-option in the evolution of a novel organ. Plant Mol Biol 2006;62:867-80.

17. Cong B, Barrero LS, Tanksley SD. Regulatory change in YABBYlike transcription factor led to evolution of extreme fruit size during tomato domestication. Nat Genet 2008;40:800-4.

18. Cong B, Liu J, Tanksley SD. Natural alleles at a tomato fruit size quantitative trait locus differ by heterochronic regulatory mutations. Proc Natl Acad Sci U S A 2002;99:13606-11.

19. Dornan D, Wertz I, Shimizu H, Arnott D, Frantz GD, Dowd P, et al. The ubiquitin ligase COP1 is a critical negative regulator of p53. Nature 2004;429:86-92.

20. Fan CC, Xing YZ, Mao HL, Lu TT, Han B, Xu CG, et al. GS3, a major QTL for grain length and weight and minor QTL for grain width and thickness in rice, encodes a putative transmembrane protein. Theor Appl Genet 2006;112:1164-71.

21. Finkelstein RR, Gampala SSL, Rock CD. Abscisic acid signaling in seeds and seedlings. The Plant Cell 2002;14:S15-45. 
22. Frary A, Nesbitt TC, Frary A, Grandillo S, van der Knaap E, Cong B, et al. fw2.2: a quantitative trait locus key to the evolution of tomato fruit size. Science 2000;289:85-8.

23. Fujisawa Y, Kato T, Ohki S, Ishikawa A, Kitano H, Sasaki T, et al. Suppression of the heterotrimeric $G$ protein causes abnormal morphology, including dwarfism, in rice. Proc Natl Acad Sci U S A 1999;96:7575-80.

24. Garcia D, Gerald JNF, Berger F. Maternal control of integument cell elongation and zygotic control of endosperm growth are coordinated to determine seed size in Arabidopsis. Plant Cell 2005; 17:52-60.

25. Garcia D, Saingery V, Chambrier P, Mayer U, Jürgens G, Berger F. Arabidopsis haiku mutants reveal new controls of seed size by endosperm. Plant Physiol 2003;131:1661-70.

26. Gehring M, Choi Y, Fischer RL. Imprinting and seed development. Plant Cell 2004;16:S203-13.

27. Gehring M, Huh JH, Hsieh TF, Penterman J, Choi Y, Harada JJ, et al. DEMETER DNA glycosylase establishes MEDEA Polycomb gene self-imprinting by allele-specific demethylation. Cell 2006; 124:495-506.

28. Giroux MJ, Shaw J, Barry G, Cobb BG, Greene T, Okita T, et al. A single gene mutation that increases maize seed weight. Proc Natl Acad Sci U S A 1996;93:5824-9.

29. Grossniklaus U, Vielle-Calzada JP, Hoeppner MA, Gagliano WB. Maternal control of embryogenesis by MEDEA, a polycomb group gene in Arabidopsis. Science 1998;280:446-50.

30. Gupta PK, Rustgi S, Kumar N. Genetic and molecular basis of grain size and grain number and its relevance to grain productivity in higher plants. Genome 2006;49:565-71.

31. Hong Z, Ueguchi-Tanaka M, Fujioka S, Takatsuto S, Yoshida S, Hasegawa $\mathrm{Y}$, et al. The rice brassinosteroid-deficient dwarf2 mutant, defective in the rice homolog of Arabidopsis DIMINUTO/DWARF1, is rescued by the endogenously accumulated alternative bioactive brassinosteroid, dolichosterone. Plant Cell 2005;17:2243-54.

32. Hong Z, Ueguchi-Tanaka M, Shimizu-Sato S, Inukai Y, Fujioka S, Shimada $\mathrm{Y}$, et al. Loss-of-function of a rice brassinosteroid biosynthetic enzyme, C- 6 oxidase, prevents the organized arrangement and polar elongation of cells in the leaves and stem. Plant J 2002;32:495-508.

33. Hong Z, Ueguchi-Tanaka M, Umemura K, Uozu S, Fujioka S, Takatsuto $\mathrm{S}$, et al. A rice brassinosteroid-deficient mutant, ebisu dwarf (d2), is caused by a loss of function of a new member of cytochrome P450. Plant Cell 2003;15:2900-10.

34. Huh JH, Bauer MJ, Hsieh T-F, Fischer RL. Cellular programming of plant gene imprinting. Cell 2008;132:735-44.

35. Joazeiro CAP, Wing SS, Huang HK, Leverson JD, Hunter T, Liu YC. The tyrosine kinase negative regulator c-Cbl as a RING-type, E2-dependent ubiquitin-protein ligase. Science 1999;286:309-12.

36. Jofuku KD, Omidyar PK, Gee Z, Okamuro JK. Control of seed mass and seed yield by the floral homeotic gene APETALA2. Proc Natl Acad Sci U S A 2005;102:3117-22.

37. Johnson CS, Kolevski B, Smyth DR. TRANSPARENT TESTA GLABRA2, a trichome and seed coat development gene of Arabidopsis, encodes a WRKY transcription factor. Plant Cell 2002;14:1359-75.

38. Khush GS. Green revolution: the way forward. Nature Rev Genet 2001;2:815-22.

39. Kinoshita T. Reproductive barrier and genomic imprinting in the endosperm of flowering plants. Genes Genet Syst 2007;82:177-86.

40. Kinoshita T, Yadegari R, Harada JJ, Goldberg RB, Fischer RL. Imprinting of the MEDEA polycomb gene in the Arabidopsis endosperm. Plant Cell 1999;11:1945-52.

41. Klucher KM, Chow H, Reiser L, Fischer RL. The AINTEGUMENTA gene of Arabidopsis required for ovule and female gametophyte development is related to the floral homeotic gene APETALA2. Plant Cell 1996;8:137-53.
42. Kohler C, Hennig L, Bouveret R, Gheyselinck J, Grossniklaus U, Gruissem W. Arabidopsis MIS1 is a component of the MEA/FIE polycomb group complex and required for seed development. EMBO J 2003;22:4804-14.

43. Kohler C, Hennig L, Spillane C, Pien S, Gruissem W, Grossniklaus $\mathrm{U}$. The polycomb-group protein MEDEA regulates seed development by controlling expression of the MADS-box gene PHERES1. Genes Dev 2003;17:1540-53.

44. Kohler C, Page DR, Gagliardini V, Grossniklaus U. The Arabidopsis thaliana MEDEA Polycomb group protein controls expression of PHERES1 by parental imprinting. Nature Genet 2005;37:28-30.

45. Li YH, Zheng LY, Corke F, Smith C, Bevan MW. Control of final seed and organ size by the DA1 gene family in Arabidopsis thaliana. Genes Dev 2008;22:1331-6.

46. Luo M, Bilodeau P, Dennis E, Peacock WJ, Chaudhury AM. Expression and parent-of-origin effects for FIS2, MEA and FIE in the endosperm and embryo of developing Arabidopsis seeds. Proc Natl Acad Sci U S A 2000;97:10637-42.

47. Luo M, Bilodeau P, Koltunow A, Dennis ES, Peacock WJ, Chaudhury AM. Genes controlling fertilization-independent seed development in Arabidopsis thaliana. Proc Natl Acad Sci U S A 1999;96:296-301.

48. Luo M, Dennis ES, Berger F, Peacock WJ, Chaudhury A. MINISEED3 (MINI3), a WRKY family gene, and HAIKU2 (IKU2), a leucine-rich repeat (LRR) kinase gene, are regulators of seed size in Arabidopsis. Proc Natl Acad Sci U S A 2005;102: 17531-6.

49. Martin A, Lee J, Kichey T, Gerentes D, Zivy M, Tatout C, et al. Two cytosolic glutamine synthetase isoforms of maize are specifically involved in the control of grain production. Plant Cell 2006; 18:3252-74.

50. Matsuoka M, Ashikari M. A quantitative trait locus regulating rice grain width. Nat Genet 2007;39:583-4.

51. Miller ME, Chourey PS. The maize invertase-deficient miniature1 seed mutation is associated with aberrant pedicel and endosperm development. Plant Cell 1992;4:297-305.

52. Mita S, Murano N, Akaike M, Nakamura K. Mutants of Arabidopsis thaliana with pleiotropic effects on the expression of the gene for $\beta$-amylase and on the accumulation of anthocyanin that are inducible by sugars. Plant J 1997;11:841-51.

53. Mizukami Y. A matter of size: developmental control of organ size in plants. Curr Opin Plant Biol 2001;4:533-9.

54. Mizukami Y, Fischer RL. Plant organ size control: AINTEGUMENTA regulates growth and cell numbers during organogenesis. Proc Natl Acad Sci U S A 2000;97:942-7.

55. Nesbitt TC, Tanksley SD. fw 2.2 directly affects the size of developing tomato fruit, with secondary effects on fruit number and photosynthate distribution. Plant Physiol 2001;127:575-83.

56. Ohad N, Margossian L, Hsu YC, Williams C, Repetti P, Fischer RL. A mutation that allows endosperm development without fertilization. Proc Natl Acad Sci U S A 1996;93:5319-24.

57. Ohad N, Yadegari R, Margossian L, Hannon M, Michaeli D, Harada JJ, et al. Mutations in FIE, a WD polycomb group gene, allow endosperm development without fertilization. Plant Cell 1999;11:407-16.

58. Ohto M, Fischer RL, Goldberg RB, Nakamura K, Harada JJ. Control of seed mass by APETALA2. Proc Natl Acad Sci U S A 2005; 102:3123-8.

59. Olszewski N, Sun TP, Gubler F. Gibberellin signaling: biosynthesis, catabolism, and response pathways. Plant Cell 2002;14:S61-80.

60. Reyes J, Hennig L, Gruissem W. Chromatin-remodeling and memory factors. New regulators of plant development. Plant Physiol 2002;130:1090-101.

61. Riefler M, Novak O, Strnad M, Schmülling T. Arabidopsis cytokinin receptor mutants reveal functions in shoot growth, leaf 
senescence, seed size, germination, root development, and cytokinin metabolism. Plant Cell 2006;18:40-54.

62. Saijo Y, Sullivan JA, Wang HY, Yang JP, Shen YP, Rubio V, et al. The COP1-SPA1 interaction defines a critical step in phytochrome A-mediated regulation of HY5 activity. Genes Dev 2003;17: 2642-7.

63. Schruff MC, Spielman M, Tiwari S, Adams S, Fenby N, Scott RJ. The AUXIN RESPONSE FACTOR 2 gene of Arabidopsis links auxin signalling, cell division, and the size of seeds and other organs. Development 2005;133:251-61.

64. Scott RJ, Spielman M, Bailey J, Dickinson HG. Parent-of-origin effects on seed development in Arabidopsis thaliana. Development 1998;125:3329-41.

65. Shomura A, Izawa T, Ebana K, Ebitani T, Kanegae H, Konishi S, et al. Deletion in a gene associated with grain size increased yields during rice domestication. Nat Genet 2008;40:1023-8.

66. Smidansky ED, Clancy M, Meyer FD, Lanning SP, Blake NK, Talbert LE, et al. Enhanced ADP-glucose pyrophosphorylase activity in wheat endosperm increases seed yield. Proc Natl Acad Sci U S A 2002;99:1724-9.

67. Song XJ, Huang W, Shi M, Zhu MZ, Lin HX. A QTL for rice grain width and weight encodes a previously unknown RING-type E3 ubiquitin ligase. Nat Genet 2007;39:623-30.

68. Sun Y, Tan MJ, Duan HJ, Swaroop MJ. SAG/ROC/Rbx/Hrt, a zinc RING finger gene family: molecular cloning, biochemical properties, and biological functions. Antioxid Redox Signal 2001;3:635-50.

69. Sundaresan V. Control of seed size in plants. Proc Natl Acad Sci U S A 2005;102:17887-8.

70. Tabuchi M, Sugiyama K, Ishiyama K, Inoue E, Sato T, Takahashi $\mathrm{H}$, et al. Severe reduction in growth rate and grain filling of rice mutants lacking OsGS1;1, a cytosolic glutamine synthetase $1 ; 1$. Plant J 2005;42:641-51.

71. Takeda S, Matsuoka M. Genetic approaches to crop improvement: responding to environmental and population changes. Nat Rev Genet 2008;9:444-57.

72. Tanabe S, Ashikari M, Fujioka S, Takatsuto S, Yoshida S, Yano M, et al. A novel cytochrome P450 is implicated in brassinosteroid biosynthesis via the characterization of a rice dwarf mutant, dwarf11, with reduced seed length. Plant Cell 2005;17:776-90.

73. Tanksley SD. The genetic, developmental, and molecular bases of fruit size and shape variation in tomato. Plant Cell 2004;16:S181-9.

74. Vilhar B, Kladnik A, Blejec A, Chourey PS, Dermastia M. Cytometrical evidence that the loss of seed weight in the miniature 1 seed mutant of maize is associated with reduced mitotic activity in the developing endosperm. Plant Physiol 2002; 129:23-30

75. Von Witzke H. Agriculture, world food security, bio-energy and climate change: some inconvenient facts. Q J Int Agricult 2008; $47: 1-4$.

76. Weber H, Borisjuk L, Wobus U. Controlling seed development and seed size in Vicia faba: a role for seed coat-associated invertases and carbohydrate state. Plant J 1996;10:823-34.

77. Werner T, Motyka V, Laucou V, Smets R, van Onckelen H, Schmülling T. Cytokinin-deficient transgenic Arabidopsis plants show multiple developmental alterations indicating opposite functions of cytokinins in the regulation of shoot and root meristem activity. Plant Cell 2003;15:2532-50.

78. Wu CY, Trieu A, Radhakrishnan P, Kwok SF, Harris S, Zhang K, et al. Brassinosteroids regulate grain filling in rice. Plant Cell 2008;20:2130-45.

79. Xiao WY, Brown RC, Lemmon BE, Harada JJ, Goldberg RB, Fischer RL. Regulation of seed size by hypomethylation of maternal and paternal genomes. Plant Physiol 2006;142:1160-8.

80. Xie Q, Guo HS, Dallman G, Fang SY, Weissman AM, Chua NH. SINAT5 promotes ubiquitin-related degradation of NAC1 to attenuate auxin signals. Nature 2002;419:167-70.

81. Xue WY, Xing YZ, Weng XY, Zhao Y, Tang WJ, Wang L, et al. Natural variation in Ghd7 is an important regulator of heading date and yield potential in rice. Nat Genet 2008;40:761-7.

82. Yoine M, Nishii T, Nakamura K. Arabidopsis UPF1 RNA helicase for nonsense-mediated mRNA decay is involved in seed size control and is essential for growth. Plant Cell Physiol 2006;47: 572-80.

83. Zamir D. Improving plant breeding with exotic genetic libraries. Nat Rev Genet 2001;2:983-9. 